\title{
Intention for Hepatitis B Vaccination among Male-to-female Transgenders in Bandung
}

\author{
Ain Izzati Khiruddin, ${ }^{1}$ Irvan Afriandi, ${ }^{2}$ Laili Aznur, ${ }^{3}$ Elsa Pudji Setiawati ${ }^{2}$ \\ ${ }^{1}$ Faculty of Medicine Universitas Padjadjaran, ${ }^{2}$ Department of Public Health Faculty of Medicine, \\ Universitas Padjadjaran, ${ }^{3}$ Department of Dental Health, Faculty of Medicine Universitas \\ Padjadjaran/Dr. Hasan Sadikin General Hospital Bandung
}

\begin{abstract}
Background: Hepatitis B is still an alarming global disease nowadays. The majority of transmission is by sexual activity during adulthood and male-to-female transgender is a high risk group. Despite protective vaccine is available, vaccination coverage among these high risk groups remained low. This study aimed to compare the differences in attitude, subjective norms, and perceived behavioral control between the intended group and unintended group for hepatitis B vaccination among male-to-female transgenders in Bandung.

Methods: A Cross-sectional study was conducted during September-November 2012 to 100 male-to-female transgenders residing in Bandung. Thirteen Likert scales validated questionnaires were used to compare the attitude, subjective norms and perceived behavioral control by their intention of hepatitis B vaccination (Theory of Plan Behavior/TPB). the respondents were recruited by the help of Srikandi Pasundan, that actively works in the issues of transgender. The inclusion criterias were they regard themselves as waria, consistent as a transgender for at least six months, residing in Bandung, and sexually active within six months. Independent variables consist of demographic characteristics and TPB construct variables. Mann Whitney Test was used to analyze the data.

Results: Among 75\% of the unvaccinated respondents, majority (70.7\%) have the intention to get hepatitis B vaccination. Mann Whitney analysis showed that there is a difference of attitude between the intended group and unintended group for hepatitis B vaccination, while there are no differences by their intention for subjective norms and perceived behavioral control.

Conclusion: The attitude influenced vaccination intention among male-to-female transgenders in Bandung [AMJ.2015;2(1):253-61]
\end{abstract}

Keywords: Hepatitis B, male-to-female transgenders, Theory of Planned Behavior, vaccination

\section{Introduction}

Hepatitis B is still an alarming global disease nowadays. As the most serious viral hepatitis infection, hepatitis $\mathrm{B}$ becomes a crucial problem and hepatitis B virus (HBV) is now become a common threat in many areas around the world, especially in Asian and African countries. Hepatitis B virus causes more than 350 million people to have chronic liver infections. ${ }^{1}$ Meanwhile, in Indonesia, hepatitis $B$ cases has been fluctuating nationally in the past few years and Indonesia has been categorized as a high endemic country for chronic hepatitis B infection. ${ }^{2}$

Hepatitis B virus or abbreviated as HBV can be transmitted by percutaneous or parenteral contact with blood or vaginal fluids and semen of infected people. Even though they can be transmitted with the same manner as human immunodeficiency virus (HIV), but HBV is 50100 times more infectious compared to HIV. ${ }^{3}$ The Center for Disease Control and Prevention (CDC) stated that the primary risk factors associated with hepatitis B infection are birth to an infected mother, unprotected sex with an infected partner and having multiple sex partners, men who have sex with men (MSM), history of other sexually transmitted disease as well as illegal injection drug use. ${ }^{4}$

Nowadays, transmission by sexual activity is the majority during young adulthood. Sex workers who have multiple sex partners, people with human immunodefieciency virus

Correspondence: Ain Izzati Khiruddin, Faculty of Medicine, Universitas Padjadjaran, Jalan Raya Bandung-Sumedang Km.21, Jatinangor, Sumedang, Indonesia, Phone: +6283821640179 Email: ain_izzati184@yahoo.com 
(HIV), and men who have sex with men are at the greater risk. ${ }^{5}$

There is a significant risk of transmission among the male-to-female transgenders and most of them do not have any specific form of sexual orientation and transgender people may identify as heterosexual, homosexual, or bisexual. There are several reasons why the male-to-female transgenders are high risk to be infected. Stigma and discrimination, exploitation, and limited access to health facilities are some of the reasons why their population is at stake. Due to discrimination, male-to-female transgender people are prone to work in informal sector like in hair salon, entertainment sector, and as sex workers. They also always move from one location to another, making them easier to transmit and get transmitted by sexually transmitted infections besides having multiple sex partners. ${ }^{6}$

According to the World Health Organization (WHO), hepatitis B is asexually transmitted infection that has a protective vaccine and the first vaccine against major human cancer available. So, vaccination becomes one of the most effective preventive measurements since 1982 in order to prevent the infection as well as its chronic consequences. ${ }^{3}$ Although vaccine programs have been successfully lead to subsequent decline in the incidence of hepatitis B, vaccination coverage for high-risk adult groups like having multiple sex partner in the past six months and MSM remains low. The CDC claimed that majority of new infections occur in the high-risk groups. ${ }^{4}$

Relevant approaches for identifying the determinant factors that facilitate or inhibit hepatitis vaccination decision making in this population are important. The Theory of Planned Behavior (TPB), as initially proposed by Ajzen (1984), assumes that there is an important determinant of behavior which is behavioral intention. According to TPB, attitude, subjective norms, and perceive behavioral control are the factors that can influence someone's intention. ${ }^{7}$

Attitude is a personal evaluation toward an action, subjective norms is how people try to act or behave in a way that gets key people (sexual partner or friends) approval and perceived behavioral control is a belief that one has the power to perform an action. ${ }^{8}$ By understanding the factors related to intention of male-to-female transgenders to get hepatitis $\mathrm{B}$ vaccination, it can be known how to approach them in order to make them all covered by the vaccines. Theory of Planned Behavior (TPB) is used widely to evaluate the factors that influence the intention especially the intention to take vaccination in order to improve the immunization coverage. ${ }^{9}$

So far in Indonesia, especially in Bandung, there is limited information that reveals the intention for hepatitis $B$ vaccination with the implementation of TPB for male-to-female transgenders who are at the greater risk of transmitting the disease. Despite of high fatality rate, there are other benefits by doing this study, i.e. avoid adverse economic burden, personal as well as social impact. ${ }^{5}$

Therefore, this study aimed to estimate the percentage of male-to-female transgenders who intend to get hepatitis B vaccination and to compare the differences of attitude, subjective norms, and perceived behavioral control between the intended group and unintended group for hepatitis B vaccination among maleto-female transgenders in Bandung. This study is expected to provide a basis for viral hepatitis $\mathrm{B}$ prevention and control programs among these populations

\section{Methods}

This study was an observational crosssectional study conducted in Bandung between September and November 2012. The population of the study was male-to-female transgenders residing in Bandung. Sample size for this study was calculated as minimum of 97 participants. Sampling technique used was snowball sampling and the respondents were recruited by the help of a Non-Government Organization (NGO) that actively works in the issues of transgenders, namely Srikandi Pasudan.

The respondents were included if (i) they regard themselves as waria (indonesian term for male-to-female transgender), (ii) being a consistent transgender for at least six months based on self disclosure, (iii) residing in Bandung, and (iv) sexually active within six months based on self disclosure. The male-tofemale transgenders who denied to participate due to various reasons were excluded from the study.

The dependent variable for this study was the intention to get hepatitis $B$ vaccination and was measured by asking 'Do you have the intention to get hepatitis B vaccine?' The response was recorded as a yes or no. Independent variables consist of demographic characteristics and TPB construct variables. Demographic characteristics include age, highest education level, living area, sexual orientation (attracted to male, attracted to 
female, both). The TPB constructs included attitude, subjective norms, and perceived behavioral control. All factors related to TPB constructs were measured by 13 agreement statements based on four-point Likert scales ranging from 1 (strongly disagree) to 4 (strongly agree). Attitude and subjective norms variables were assessed through five statements each, while perceived behavioral control variable was measured by three statements. The content validity of questionnaire was examined by the expert whereas its face validity was assessed by the transgender NGO activist.

Results of reliability test showed that the Cronbach's alphas of attitude, subjective norms and perceived behavioral controls subscales altogether were 0.72. All data were collected through a self-administered questionnaire. After getting the permission from the local authority, letters of consent were given to all selected participants and information regarding the study was explained in detail. The questionnaires were distributed after the participants were fully informed about the survey and have signed the letter of consent. After completing the questionnaire, the researcher checked its completeness. Incomplete data were returned to the respondents to be completed.

All data collected were entered and analyzed using computer. Univariate analysis by descriptive statistics was used to describe the distributions of background and components of TPB outcome variables among study respondents in the forms of frequency distribution and percentage. Bivariate analyses were used to assess the difference between components of TPB (attitude toward behavior, subjective norm, and perceived behavioral control) and the outcome variable, which is the intention of getting hepatitis $\mathrm{B}$ vaccination among the male-to-female transgenders in Bandung.

Table 1 Characteristics of Study Subjects

\begin{tabular}{lcc}
\hline \multirow{2}{*}{ Characteristics } & Male-to-female transgender & (n=100) \\
\cline { 2 - 3 } & f & \% \\
\hline Highest Education level & 10 & 10.0 \\
Pre school & 47 & 47.0 \\
Primary school & 42 & 42.0 \\
Secondary school & & \\
Living area & 95 & 95.0 \\
Municipal & 5 & 5.0 \\
District & & \\
Ethnicity & 73 & 73.0 \\
Sunda & 17 & 17.0 \\
Jawa & 9 & 9.0 \\
Batak & 1 & 1.0 \\
Others & & \\
Occupation & 43 & 43.0 \\
Salon & 22 & 22.0 \\
Sex worker & 10 & 10.0 \\
Self employed & 17 & 17.0 \\
Unemployed & 8 & 8.0 \\
Busker & & \\
Sexual attraction & 99 & 99.0 \\
Men only & 1 & 1.0 \\
Men and women & &
\end{tabular}




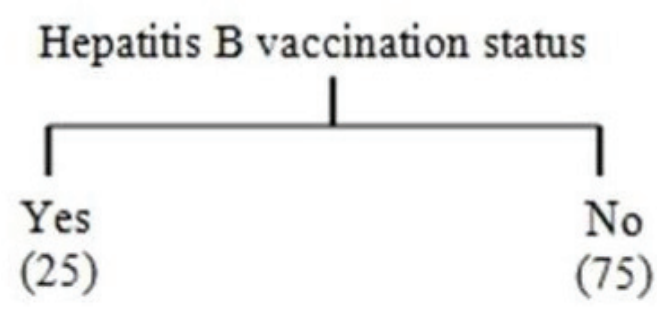

Intention to get hepatitis B

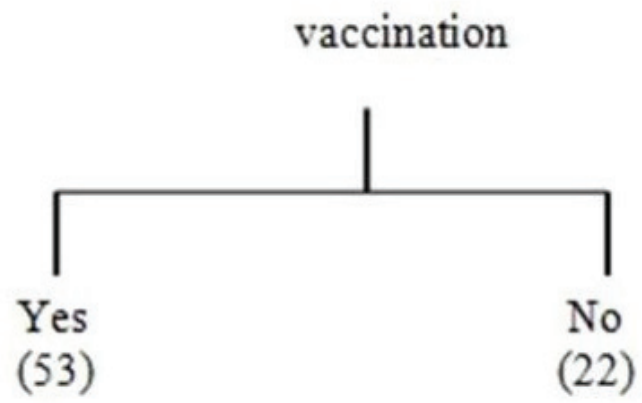

Figure 1 Participation of Study Subjects

Since the data were not normally distributed, Mann-Whitney Test was used to compare the median scores for Likert items measuring TPB components across respondents by intention to take hepatitis $\mathrm{B}$ vaccination. Confounding factors that are being considered were age and highest educational level. Several interview sessions to a few selected informants were conducted after the quantitative dataset was analyzed for triangulation.

The ethical clearance for this study was issued by the Health Research Ethic Committee, Faculty of Medicine, Universitas Padjadjaran. (No 319/UN6.C2.1.2/KEPK/2012) dated on 28 November 2012.

\section{Results}

One hundred respondents participated in this study. Age for male-to-female transgenders in Bandung was quite varied, the age ranged from 20 to 58 years old. Mean age for the respondent was 31 (standard deviation=9.56).

Based on the highest education level, the number of male-to-female transgenders whose education is primary school and secondary school are comparable. Almost all respondents were living in Bandung municipal area and were Sundanese. More than forty percents of the respondents worked at beauty salon, while the rest worked as sex workers and self-employed. Almost all male-to-female transgenders were attracted to men

Out of one hundred respondents, only 25\% were already vaccinated against hepatitis B and the rest remained unvaccinated. From 75 respondents who had not get the vaccination, when asked 'Do you have the intention to get hepatitis B vaccination', only 22 male-to-female transgenders $(29.3 \%)$ did not demonstrate a clear intention to get vaccinated against hepatitis B by giving the answer 'no'. Those are shown in detail in the next figure. Those who had already been vaccinated against hepatitis $B$ were excluded for further analysis.

Mean age for group of respondents with hepatitis B vaccination status 'No" was slightly younger 30 (standard deviation=9.16). Their age ranged from 20 to 58 years old. Besides age, other demographic characteristics for those who had not yet vaccinated are presented in the table 2.

Table 3 shows the complete results according to each statement regarding TPB determinant construct which are attitude, subjective norms, and perceived behavioral control. The evaluations towards hepatitis B vaccination among male-to-female transgenders are illustrated in percentage in the next table. 
Table 2 Demographic Characteristics for Those who Have not yet Vaccinated

\begin{tabular}{lcc}
\hline \multirow{2}{*}{ Characteristics } & Male-to-female transgender & (n=75) \\
\cline { 2 - 3 } & f & \% \\
\hline Highest education level & 5 & 6.7 \\
Pre school & 39 & 52.0 \\
Primary school & 30 & 40.0 \\
Secondary school & & \\
Living area & 72 & 96.0 \\
Municipal & 3 & 4.0 \\
District & & \\
Ethnicity & 53 & 70.7 \\
Sunda & 15 & 20.7 \\
Jawa & 6 & 8.0 \\
Batak & 1 & 1.3 \\
Others & & \\
Sexual attraction & 74 & 98.7 \\
Men only & 1 & 1.3 \\
Men and women & & \\
Occupation & 31 & 41.3 \\
Salon & 17 & 22.7 \\
Sex worker & 10 & 13.3 \\
Self employed & 13 & 17.3 \\
Unemployed & 4 & 5.3 \\
Busker & &
\end{tabular}

Bivariate analysis illustrated the result of nonparametric test, Mann-Whitney Test towards the components of TPB with the intention of hepatitis B vaccination are shown in the Table 4 in testing the predictive utility of Theory of Planned Behavior as the framework for understanding vaccination motivating and inhibiting factors. The result implied that attitude exert a stronger influence over this decision making process than their subjective norms or perceived behavioral control. Tables 4 describes the result in more details.

Two characteristics variables were concerned to be potential confounding factors; those were age (median 30 years) as well as highest education level. After conducting stratified analysis of attitude on those two potential confounding factors, the result showed that the level of education was proven as a confounding factor.

\section{Discussions}

Attitude among the male-to-female transgenders in Bandung were assessed by using five questions. Table 3 shows the complete result and illustration about attitude of male-to-female transgenders towards hepatitis B vaccination. Majority of the respondents believe that they are at risk of getting hepatitis B infection in which $(70.7 \%)$ agree and strongly agree (1.3\%). Nearly $90 \%$ agree that vaccination can protect them from getting the infection.

According to a study informant (35 years old, NGO Srikandi Pasundan), most of the maleto-female transgenders felt they are at risk because they kow that injecting drug users are high risk to get hepatitis B and some of their sexual partners and friends are injecting drug 
Table 3 Percentages of Respondents According to the Statements based on TPB Components

\begin{tabular}{|c|c|c|c|c|c|}
\hline & \multirow{2}{*}{ Statements $(n=75)$} & SD & D & A & SA \\
\hline & & $\%$ & $\%$ & $\%$ & $\%$ \\
\hline & Attitude & & & & \\
\hline 1 & I believed I am at risk of getting hepatitis B & 0.0 & 28.0 & 70.7 & 1.3 \\
\hline 2 & $\begin{array}{l}\text { I believed by vaccination I can protect myself against } \\
\text { hepatitis B infection }\end{array}$ & 0.0 & 10.7 & 77.3 & 12.0 \\
\hline 3 & $\begin{array}{l}\text { I believed by vaccination I can protect my sexual partner } \\
\text { from hepatitis B infection }\end{array}$ & 0.0 & 8.0 & 76.0 & 16.0 \\
\hline 4 & $\begin{array}{l}\text { I am afraid hepatitis B vaccination will cause unpleasant } \\
\text { side effects }\end{array}$ & 0.0 & 37.3 & 57.3 & 5.3 \\
\hline 5 & I don't need hepatitis B vaccination & 1.3 & 62.7 & 34.7 & 1.3 \\
\hline & Subjective norms & & & & \\
\hline 6 & $\begin{array}{l}\text { My sexual partner thinks it is important for me to take } \\
\text { hepatitis B vaccination }\end{array}$ & 2.7 & 21.3 & 68.0 & 8.0 \\
\hline 7 & $\begin{array}{l}\text { Hepatitis B vaccination is not a common thing among } \\
\text { male-to-female transgenders }\end{array}$ & 0.0 & 34.7 & 53.3 & 12.0 \\
\hline 8 & $\begin{array}{l}\text { The costs for hepatitis B vaccination is unaffordable for } \\
\text { male-to-female transgenders }\end{array}$ & 0.0 & 9.3 & 80.0 & 10.7 \\
\hline 9 & $\begin{array}{l}\text { The schedule for hepatitis B vaccination is a hassle for a } \\
\text { male-to-female transgender like me }\end{array}$ & 1.3 & 16.0 & 70.7 & 12.0 \\
\hline 10 & $\begin{array}{l}\text { I am motivated to take hepatitis } B \text { vaccination if other } \\
\text { male-to-female transgender took the vaccination }\end{array}$ & 0.0 & 20.0 & 70.7 & 9.3 \\
\hline & Perceived behavioral control & & & & \\
\hline 11 & $\begin{array}{l}\text { No one can arrange my decision to get hepatitis B } \\
\text { vaccination }\end{array}$ & 2.7 & 33.3 & 57.3 & 6.7 \\
\hline 12 & $\begin{array}{l}\text { I have control over whether or not I get the hepatitis B } \\
\text { vaccination }\end{array}$ & 0.0 & 24.0 & 69.3 & 14.7 \\
\hline 13 & $\begin{array}{l}\text { I need a visit from health care workers to vaccinate me } \\
\text { against hepatitis B }\end{array}$ & 0.0 & 14.7 & 70.7 & 14.7 \\
\hline
\end{tabular}

Note: $\mathrm{SD}=$ Strongly Disagree, $\mathrm{D}=$ Disagree, $\mathrm{A}=$ Agree, $\mathrm{SA}=$ strongly agree

users. Unfortunately, the study informant (35 years old, NGO Srikandi Pasundan), claimed that most of the male-to-female transgenders still do not realize that men who have sex with men and having multiple sex partner increase the chance of getting hepatitis $\mathrm{B}$ infection and the mode of transmission of the disease was still poorly understood. Nearly all of the respondents (92\%) agreed that by vaccination they can protect their sexual partner/s against hepatitis B infection.

However, more than half of the respondents $(62.7 \%)$ believe that hepatitis B vaccination causes unpleasant side effects. This wrong perception was also discussed by Jay A. Jacob in his article that beliefs about safety of the vaccine, beliefs that coincidental symptoms they experienced after the vaccination were caused by it as well as perceive risks and consequences of contracting the disease after vaccination are powerful determinants for vaccination among adults. ${ }^{10}$ Even when more than half of the male-to-female transgenders $(64 \%)$ disagree that they do not need the vaccination, the rests of them still think that they do not need vaccination. The misperceptions and ignorance about vaccinepreventable disease and vaccine itself may reduce the desire for vaccination and denial to their use.$^{10}$ The study informant (35 years old, NGO Srikandi Pasundan) said that because hepatitis B is not as famous as other sexually transmitted disease and takes a quite long time to show the effects, they tend to ignore the disease.

Meanwhile, subjective norms were 
Ain Izzati Khiruddin, Irvan Afriandi, Laili Aznur, Elsa Pudji Setiawati: Intention for Hepatitis B Vaccination 259 among Male-to-female Transgenders in Bandung

determined by wishes or perceived pressure by the important people or surrounding. Five questions regarding subjective norms were answered and the results are listed in table $1 .^{3}$ and $76 \%$ agree their sexual partners thought it is important for them to get hepatitis B vaccination. ${ }^{10}$ The study informant (35 years old, NGO Srikandi Pasundan) claimed that sexual clients or their partners usually encourage them to do positive actions especially when it is related with health. Social support as well as relationship could have a significant effects on health and research supported the idea that cohesive communities often experience a better health outcome.11

A large number of respondents (65.3\%) thought that hepatitis $B$ vaccination is not a common thing among male-to-female transgenders. This situation might be duetolack of exposure or recommendations for vaccine and less peer dialogue about the hepatitis B vaccination, leading to a consideration that it is an to unusual phenomena if someone among the group has the vaccination. ${ }^{10}$

From the study informant's (35 years old, NGO Srikandi Pasundan) point of view, most of male-to-female transgenders tend to ignore hepatitis $B$ because the organ affected is liver and not as visible as the genital. However, if most of their male-to-female transgender friends have already been vaccinated and gained benefits from it they usually want to be vaccinated too. This is relevant to the statement that transgenders are motivated to take hepatitis B vaccination if other male-tofemale transgenders took the vaccination and nearly $80 \%$ of them agree with the statement. Regarding the cost for vaccination, almost all respondents $(90.7 \%)$ thought that the cost were unaffordable for them.

According to Lisa Curran ${ }^{12}$ in her article, vaccine cost could be one of the contributing factors to the low coverage of vaccination among adults. The study informant (35 years old, NGO Srikandi Pasundan) said that it is true that money is the main concern for maleto-female transgenders but the reason why $9.3 \%$ disagree was if they were convinced that the vaccine was really important for them, they would took it no matter how much it cost. Since male-to-female transgenders are highly mobile and living in an erratic work time schedule, majority of the respondents $(82.7 \%)$ thought the schedule for hepatitis B vaccination is a hassle for a male-to-female transgender like them since they need to get three doses at certain period of time.

For measuring perceived behavioral control, using three questions were used and each of the questions were built to see the self evident and reflected the belief that one has the power to perform the behavior and the result is illustrated in table 3 . More than half of the respondents (64\%) thought no one can tell them about their decision whether they want to get hepatitis $B$ vaccination and more than two third of the respondents (76.4\%) felt that they have control over whether or not they get the hepatitis B vaccination. However, $85.4 \%$ of the male-to-female transgenders need a visit from health care workers to vaccinate them against hepatitis $\mathrm{B}$.

According to the study informant (35 years old, NGO Srikandi Pasundan), it will be more effective if the vaccination was done to a group of male-to-female transgenders rather than they have to search for vaccination service individually. A study in Ghent Belgium ${ }^{13}$ shows that an outreach program performed to improve hepatitis $\mathrm{B}$ vaccination among sex workers results in $82.8 \%$ of $t$ eligible sex workers started with a first vaccine dose and $71.5 \%$ received the second dose.

This study has demonstrated that there are significant differences in attitude between the intended group and unintended group to vaccinate against hepatitis $B$. They really believed they are at risk of getting hepatitis $B$ and they know that there is a vaccine that can protect them and their sexual partner against the disease. They are also aware that they need the vaccine but there is still a high number of respondents who are afraid that hepatitis B vaccination will cause unpleasant side effects. Similar to a study conducted in Illinois, when applying the TPB, between all of the variables only attitudes exhibiting the strongest relationship, it is concluded that positive attitude was a major predictor for a better outcome $\mathrm{e}^{14}$. However, the differences in attitudes are influenced by educational level.

Furthermore, subjective norms and perceived behavioral control have no significant difference between the intended group and unintended group to get hepatitis $B$ vaccination. Even though approval of key people like their male-to-female transgender friends play a major role in motivating them to take the vaccination but it is not enough to show a significant difference in subjective norms by the intention to get the vaccination. Reasons presented by the study informant (35 years old, NGO Srikandi Pasundan) regarding negative differences of subjective norms and perceived behavioral control are male-tofemale transgenders are inconsistent and 
usually depends and follow their guardian or their "mummy". Approval from their guardian plays a major role in their decision making and is not included in the study. A study performed to predict intention for Human Papilloma Virus (HPV) vaccination also reported that levels of perceived behavioral control have no effects on the intention while attitudes arethe strongest factor of the intention. ${ }^{15}$

The central questions of this study concerned with what factors inhibiting and facilitating intention of hepatitis B vaccination among male-to-female transgenders in Bandung. Although the result showed only attitudes show a significant different between theory driven measures of TPB and the intention to get hepatitis B vaccination among sample of male-to-female transgenders in Bandung but from the questions, it could be dig out what influence the reluctance of maleto-female transgenders from getting hepatitis $B$ vaccination. This indicates that TPB does provide a useful theory driven framework for understanding the determinants when maleto-female transgenders deciding to vaccinate against hepatitis $\mathrm{B}$.

Judging from the fairly high rates of intention to get hepatitis $B$ vaccination among male-to-female transgenders in Bandung, Social Affairs and Health Offices should work together to create an integrated extension outreach program for vaccination along with routine check up for sexually transmitted disease for this high risk group.

Education highlighting how to change the attitude that acts as major predictor for better outcome should be given. Routine counselling on hepatitis B and other sexually transmitted diseases to the male-to-female transgenders with the cooperation between public health authorities and NGOs (such as Srikandi Pasundan) should be carried out during their routine meeting every Monday morning in order to increase understanding about the disease.

Coordination can be done by the committee of Srikandi Pasundan. Education in the form of videos and songs are more effective compared to brochure and pamphlet, according to the study informant (35 years old, NGO Srikandi Pasundan). Further studies should investigate whether interventions targeting the attitudes towards hepatitis B vaccination impact maleto-female transgenders' intention to receive a hepatitis B vaccination and hepatitis B vaccination uptake action.

The study has some limitations such as questionnaire data is inevitably subjected to some error and response bias because it relies heavily on accurate self-reporting though care was taken to ensure anonymous data collection and thus encourage accurate questionnaire responses.

\section{References}

1. CDC. World hepatitis day-July 28th. Washington: Center for Disease Control and Prevention; 2011. [Cited 2012 April 18]. Available from: http://www.cdc.gov/ Feature/dsHepatitisAwareness/

2. DepKes. Profil kesehatan Indonesia. Jakarta: Departemen Kesehatan Indonesia; 2007.

3. WHO. Hepatitis B. Geneva: World Health Organization; 2008. [Cited 2012 April 17]. Available from: http://www.who.int/ mediacentre/factsheets/fs204/en/

4. CDC. Hepatitis B information for health professionals. Atlanta: Center for Disease Control and Prevention; 2012. [Cited 2013 February 7]. Available from: http:/www. cdc.gov/hepatitis/HBV

5. Australian Government Department of Health and Ageing. National Hepatitis B strategy 2010-2013. 2010 [Cited 2012 April 21]. Available from: http://www. health.gov.au/internet/main/publishing. nsf/Content/ohp-national-strategies2010-hepb

6. Wahyuddin. Faktor-faktor yang memengaruhi keputusan waria melakukan tes HIV/AIDS pasca konseling HIV/AIDS di Klinik IMS dan VCT Veteran Medan [dissertation]. Medan: Universitas Sumatera Utara; 2010.

7. Ajzen I. Behavioral interventions based on the theory of planned behavior. 2006 [Cited 2012 April 17]. Available from: http://people.umass.edu/aizen

8. Rimer B, Glanz K. Theory at glance 2005. 2nd ed. U.S. Department of Health and Human Services National Institutes of Health; 2005.

9. Gallagher S, Povey R. Determinants of older adults' intentions to vaccinate against influenza: a theoretical application. J Public Health (Oxf). 2006;28(2):139-44

10. Jacobson JA. Residents' role in immunizing adults: Rationale, Opportunity, Obstacles, and Strategies. Virtual Mentor. 2012;1(14):23-9.

11. Story CR. Influenza Immunization Status Among African Americans: Factors Influencing Vaccine Decisions [dissertation].Knoxville: University of 
Tennessee; 2012.

12. AAFP. Vaccination coverage in adults remains low, says CDC. American Family Physicians; 2012 [Cited 17 April 2012]. Available from: http://www.aafp.org.

13. Mak R, Traen A, Claeyssens M, Van Renterghem L, Leroux-Roels G, VanDamme P. Hepatitis $B$ vaccination for sex workers: do outreach programmes perform better? Sex Transm Infect. 2003 Apr;79(2):157-9.

14. Rah JH, Hasler CM, Painter JE, Chapman-
Novakofski KM. Applying the theory of planned behavior to women's behavioral attitudes on and consumption of soy products. J Nutr Educ Behav. 2004;36(5):238-44.

15. Askelson NM, Campo S, Lowe JB, Smith S, Dennis LK, Andsager J. Using the theory of planned behavior to predict mother's intention to vaccinate their daughters against HPV. J Sch Nurs. 2010;26(3):194202 